\title{
Padrão Molecular e de Virulência de Isolados de Pyricularia grisea do Estado do Rio Grande do Sul
}

\author{
João L. N. Maciel ${ }^{1}$, Paula C. S. Rodrigues ${ }^{1}$, Oneides A. Avozani ${ }^{1}$ \& Marcelo G. Moraes $^{2}$ \\ ${ }^{1}$ Estação Experimental do Arroz, Instituto Rio-Grandense do Arroz (EEA-IRGA), CEP 94930-030, Cachoeirinha, RS, e-mail: \\ jomac_irga@redemeta.com.br; ${ }^{2}$ Departamento de Fitossanidade, Faculdade de Agronomia, Universidade Federal do Rio \\ Grande do Sul, Cx. Postal 776, CEP 90001-970, Porto Alegre, RS, e-mail:mgm@ufrgs.br
}

(Aceito para publicação em 04/03/2004)

Autor para correspondência: João L. Nunes Maciel

MACIEL, J.L.N., RODRIGUES, P.C.S., AVOZANI, O.A. \& MORAES, M.G. Padrão molecular e de virulência de isolados de Pyricularia grisea do Estado do Rio Grande do Sul. Fitopatologia Brasileira 29:504-510. 2004.

\section{RESUMO}

A obtenção de genótipos resistentes à brusone é uma das maiores dificuldades para os programas de melhoramento genético de arroz (Oryza sativa) devido à variabilidade do fungo Pyricularia grisea. Esta diversidade do fungo tem sido caracterizada por meio de marcadores moleculares de DNA e pela virulência de isolados do patógeno demonstrada em genótipos de arroz com diferentes genes de resistência à brusone. Os marcadores moleculares permitem identificar isolados de $P$. grisea em grupos geneticamente relacionados denominados de linhagens e as linhas isogênicas em grupos com padrões de virulência iguais ou muito similares. Assim, este trabalho foi realizado com os objetivos de verificar os padrões moleculares e de virulência de isolados de P. grisea do Rio Grande do Sul. O DNA de 51 isolados monospóricos de P. grisea obtidos do Rio Grande do
Sul foi utilizado em reações de PCR com os oligonucleotídeos iniciadores baseados na seqüência repetitiva Pot2. Os mesmos isolados também foram utilizados para inocular plantas de seis linhas isogênicas de arroz. A análise estatística indicou a ocorrência de seis linhagens e sete grupos de virulência. A ocorrência de isolados que causam reações de compatibilidade em linhas isogênicas que contêm o alelo $\mathrm{Pi}-1$ foi maior do que aquelas que possuem o alelo $\mathrm{Pi}$-2. As reações de compatibilidade na linha isogênica C 101 A51 caracterizaram-se pela baixa severidade, em geral, avaliadas como sendo de nota 4. Não foi verificada uma relação direta entre os padrões moleculares e de virulência dos isolados avaliados.

Palavras-chave adicionais: Magnaporthe grisea, similaridade, patotipos.

\section{ABSTRACT}

Molecular pattern and virulence of Pyricularia grisea from the State of Rio Grande do Sul

Selection for rice blast resistance is a major problem in any rice (Oryza sativa) breeding program due to the variability of the fungus Pyricularia grisea. This diversity has been characterized by DNA molecular markers and by virulence of the isolates that has been demonstrated on rice genotypes with different blast resistance genes. Molecular markers allow the identification of groups of isolates, so called lines, genetically related to each other, and the isogenic lines (NILs) in groups of virulence with the same or similar virulence pattern. The objectives of this work were to verify the molecular and virulence patterns from isolates of $P$. grisea from the State of Rio Grande do Sul. The DNA from 51 monosporic isolates obtained in Rio Grande do Sul were used in PCR reactions with primers based on the repetitive sequence Pot2. The same isolates were also used to inoculate six NILs. The statistical analysis indicates the presence of six lines and seven virulence groups. The frequency of virulent isolates is higher in the NIL that contains the $P i-1$ allele and lower in the NIL containing the $\mathrm{Pi}-2$ allele. The compatible reaction on the NIL that carries $P i-2$ is very weak, exhibiting, in general, a type 4 reaction. No obvious relationship between phenotypic virulence and line determination has been found.

\section{INTRODUÇÃO}

No Rio Grande do Sul, uma das principais medidas recomendadas para o controle da brusone de arroz (Oryza sativa L.), causada pelo fungo Pyricularia grisea (Cooke) Sacc., tem sido a utilização de cultivares resistentes. No entanto, a maior dificuldade para a adoção dessa estratégia é a "quebra” ou "perda" de resistência da cultivar lançada, o que normalmente ocorre três a quatro anos após seu cultivo contínuo e intenso. De acordo com Levy et al. (1993), as prováveis causas para que os genótipos tornem-se suscetíveis à doença são a ocorrência de trocas genéticas no patógeno gerando formas diferentes de virulência ou o aumento da freqüência de patótipos do fungo de ocorrência rara. Para estudar e compreender a diversidade do patógeno, tem-se realizado ensaios de patogenicidade que classificam isolados em raças através das reações que provocam em um conjunto de oito genótipos de arroz com resistência diferencial (Atkins et al., 1967).

A partir do início da década de 1990, iniciou-se o processo de classificação do fungo utilizando marcadores moleculares de DNA baseados em sondas de RFLP (polimorfismo baseado no tamanho do fragmento de restrição) que hibridizam de forma específica com o DNA de P. grisea. Com isso tem sido possível classificar grupos de isolados de P. grisea com padrões de bandas de DNA com similaridade 
Padrão molecular e de virulência de isolados de Pyricularia grisea...

superior a $85 \%$ em grupos geneticamente relacionados denominados de linhagens. Entre outros locais, esta técnica foi usada para caracterizar a população de $P$. grisea na Colômbia, nos Estados Unidos e nas Filipinas (Levy et al., 1991; Correa-Victoria \& Zeigler, 1993; Chen et al., 1995; Zeigler et al., 1995). Uma alternativa ao uso da técnica de RFLP tem sido a amplificação de regiões espaçadoras entre as seqüências repetitivas Pot2 (SR-Pot2) através da técnica de reação em cadeia da polimerase (PCR). Esta estratégia tem gerado polimorfismo compatível com a identificação das linhagens do patógeno (Kachroo et al., 1994; George et al., 1998) permitindo que também seja adotada para caracterizar a população do fungo no Brasil (Prabhu et al., 2002). Além disso, o polimorfismo produzido quando se utiliza a SR-Pot2 como marcador molecular é considerado elucidativo do fluxo gênico na população de P. grisea em eventos de recombinação, seja por modo sexual ou parassexual (George et al., 1998).

Linhas isogênicas de arroz têm sido muito utilizadas para determinação do espectro de virulência da população do patógeno devido, principalmente, à presença de um único alelo de resistência conhecido em cada um desses genótipos (Inukai et al., 1994). A reação de linhas isogênicas também tem tornado possível determinar quais são os alelos de resistência mais eficazes, de diferentes genes, para controlar a doença no local onde os isolados monospóricos do patógeno foram obtidos (Chen et al., 1995; Mekwatanarkarn et al., 2000; Filippi \& Prabhu, 2001).

Assim, este trabalho foi realizado com os objetivos de verificar os padrões moleculares e de virulência de isolados de P. grisea do Estado do Rio Grande do Sul.

\section{MATERIALEMÉTODOS}

\section{Obtenção e preservação de isolados monospóricos}

Os isolados de $P$. grisea foram obtidos de plantas de arroz coletadas de diversas lavouras e parcelas experimentais do interior do Rio Grande do Sul entre os anos de 1996 e 2001. De cada amostra, folhas, colmos ou panículas foram colocados em câmara úmida, a $27^{\circ} \mathrm{C}$. Nestas condições, ocorreu a esporulação do patógeno nas lesões permitindo que se realizasse, com o auxílio de um microscópio e de uma agulha entomológica, a transferência de esporos para placas de Petri contendo o meio de cultura ágar-água. Após 24 h, a $27^{\circ} \mathrm{C}$, entre um a quatro esporos germinados em cada amostra foram individualmente transferidos para placas de Petri contendo meio de cultura sólido de arroz polido (SAP) descrito por Tuite (1969). Depois de permanecerem a $28^{\circ} \mathrm{C}$, por seis a oito dias, as colônias obtidas foram utilizadas como fonte para futuras transferências do fungo.

A preservação dos isolados foi realizada através do preenchimento de placas de Petri, contendo meio SAP, com vários pedaços de papel-filtro esterilizados $(2 \times 2 \mathrm{~cm})$. Após, pequenos agregados de micélio do fungo (2-3 mm), obtidos através da raspagem das colônias crescidas em meio SAP, foram depositados em cada um dos pedaços do papel-filtro. Após a incubação por seis a oito dias, a $28^{\circ} \mathrm{C}$, os pedaços de papel foram armazenados a $-20^{\circ} \mathrm{C}$. A partir do fungo preservado em papel-filtro é que se obteve a maioria das colônias do patógeno necessárias para execução dos procedimentos realizados neste trabalho.

\section{Reações de amplificação e eletroforese}

A partir de colônias crescidas por três a quatro dias, a $27^{\circ} \mathrm{C}$, em meio SAP, hifas do fungo foram coletadas com uma alça e transferidas para Erlenmeyers contendo o meio líquido modificado de Fries (Van Etten \& Daly, 1980) enriquecido com vitaminas. Os isolados foram incubados durante dez a 12 dias, a $27^{\circ} \mathrm{C}$, com agitação constante de 100 RPMs. Neste período ocorreu o crescimento do micélio para ser usado na extração de DNA. O DNA dos isolados, o qual foi extraído pelo método do acetato de potássio (Scoot et al., 1993), foi utilizado em reações de PCR utilizando oligonucleotídeos iniciadores baseados na SR-Pot2 (Kachroo et al., 1994). Os produtos das amplificações foram submetidos à eletroforese, em géis de agarose, a 0,5\%, a $120 \mathrm{~V}$. Os géis foram corados em solução de $0,5 \mu \mathrm{g} / \mathrm{ml}$ de brometo de etídio, por $15 \mathrm{~min}$. Utilizou-se o programa estatístico NTSYS para construção das matrizes de similaridade e do dendrograma, o qual foi feito pelo coeficiente de Jaccard e pelo método UPGMA, respectivamente (Sneath \& Sokal, 1973; Kachroo et al., 1994).

\section{Testes de virulência}

A determinação do espectro de virulência dos isolados de $P$. grisea foi realizada através da inoculação em plantas das linhas isogênicas C 101 A51, C 101 PKT, C 104 LAC, C 104 PKT, C 105 TTP e IR 1529 (MacKill \& Bonman, 1992). Plantas das cultivares Fanny e Oryzica Llanos 5 também foram utilizadas no experimento como padrões devido às reações de suscetibilidade e resistência que tem demonstrado, respectivamente, quando submetidas a inoculações com isolados do Brasil e da América do Sul (Correa-Victoria \& Zeigler, 1993; Filippi \& Prabhu, 2001). Vinte plantas de cada genótipo, distribuídas em dois vasos com igual número de plantas e contendo solo de lavoura, foram submetidas à inoculação para cada isolado. Aplicou-se nitrogênio na proporção correspondente a $180 \mathrm{Kg}$ de N/ha, sob a forma de uréia, em três doses com quantidades iguais aos dez e 16 dias depois do plantio e um dia antes da inoculação. As inoculações foram realizadas quando as plantas apresentavam três a quatro folhas expandidas, com 15 a $25 \mathrm{~cm}$, em torno de 22 dias após o plantio. Em cada câmara de plástico, onde ficavam acondicionados 16 vasos, utilizaram-se $20 \mathrm{ml}$ de suspensão com $1,8 \times 10^{5}$ conídios/ $\mathrm{ml}$. As plantas permaneceram nas câmaras, por 14 dias, em casa de vegetação, a $28{ }^{\circ} \mathrm{C}$, até serem avaliadas. A reação à doença dos diferentes genótipos foi realizada considerando o tipo de lesão e a área foliar afetada de acordo com a escala diagrámática preconizada pelo sistema internacional de avaliação de doenças do arroz (International Rice Research Institute, 1996). As reações em cada linha isogênica foram consideradas compatíveis quando apresentavam nota igual ou superior a 4. Entretanto, as reações dos genótipos também foram consideradas compatíveis quando pelo menos $20 \%$ das 
plantas avaliadas apresentavam lesões esporulativas em mais de 5\% da área foliar. A comparação entre os espectros de virulência dos isolados foi realizada de acordo com os tipos de reações proporcionadas pelos isolados em cada linha isogênica. Organizou-se uma matriz binária estabelecendo que as reações de compatibilidade e incompatibilidade fossem caracterizadas pelos valores numéricos absolutos de 1 e 0 (zero), respectivamente. O programa estatístico NTSYS foi utilizado para a construção das matrizes de similaridade e do dendrograma, que foram estabelecidos pelo coeficiente de Dice e pelo método UPGMA, respectivamente (Filippi \& Prabhu 2001; Sneath \& Sokal, 1973).

\section{RESULTADOS}

Os 51 isolados monospóricos utilizados neste trabalho foram obtidos de amostras de plantas de 25 genótipos distintos, provenientes de lavouras, ou parcelas experimentais, instaladas em 12 municípios do Rio Grande do Sul, entre os anos de 1996 e 2001 (Figura 1). O DNA amplificado destes isolados gerou pelo menos 27 bandas polimórficas com pesos moleculares variando de 0,4 a 25Kb (Figura 2). Entretanto, foram utilizadas 24 bandas para a construção do dendrograma referente à análise molecular hierárquica entre isolados. Algumas bandas foram desconsideradas devido à baixa nitidez que as mesmas apresentavam em muitos dos géis obtidos. $\mathrm{O}$ número de linhagens formadas foi seis, as quais estão representadas no dendrograma da relação genética entre isolados pelas letras A até F (Figura 3A). Considerou-se que os isolados pertenciam a uma mesma linhagem quando apresentassem, entre si, similaridade superior a 65\%. Esta porcentagem é diferente daquela utilizada quando se empregou, através da técnica de RFLP, a seqüência MGR586 como marcador molecular, em que a similaridade mínima entre os isolados componentes de cada linhagem foi de 85\% (Levy et al., 1993; Xia et al., 1993). Esta opção foi adotada em função dos resultados obtidos por George et al. (1998), os quais, utilizando a SR-Pot2 como marcador molecular, verificaram que, com 65\% de similaridade mínima para definição dos grupos, foi possível determinar que as linhagens obtidas eram iguais àquelas determinadas pelo uso da seqüência MGR586 como marcador molecular. Assim, verificou-se que a grande maioria dos isolados testados pertence a duas linhagens somente, ou seja, dos 51 isolados utilizados neste experimento, 24 e 19 foram classificados como pertencentes às linhagens $\mathrm{E}$ e F, respectivamente. $\mathrm{O}$ número de isolados pertencentes às linhagens A, B, C e D foi de 1, 1, 5 e 1, respectivamente.

A analise hierárquica do padrão de virulência dos isolados determinou a formação de sete grupos os quais foram denominados de grupos de virulência e identificados pelas letras a’ até g' (Figura 3B). Este agrupamento dos isolados foi realizado considerando que a similaridade mínima entre os componentes de cada grupo fosse de $80 \%$, tal como fora estabelecido por Filippi \& Prabhu (2001). A reação dos genótipos Fanny e Oryzica Llanos 5 não influenciou na definição dos grupos de virulência determinado pela análise

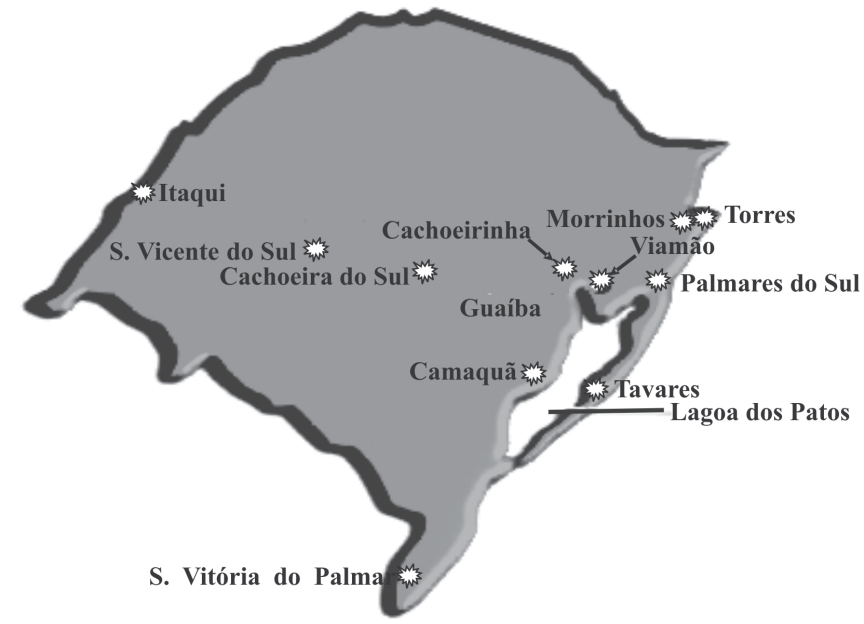

FIG. 1 - Mapa do Estado do Rio Grande do Sul indicando os municípios em que foram obtidos os isolados de Pyricularia grisea.

hierárquica uma vez que as reações provocadas por todos os isolados nos dois genótipos foi de compatibilidade e incompatibilidade, respectivamente. Os isolados dos grupos de virulência d' e g' foram aqueles que apresentaram maior espectro de virulência uma vez que produziram reações de compatibilidade em quatro das seis linhas isogênicas avaliadas. A que apresentou menor espectro foi o grupo a' que provocou reações de compatibilidade somente na linha isogênica C 104 LAC.

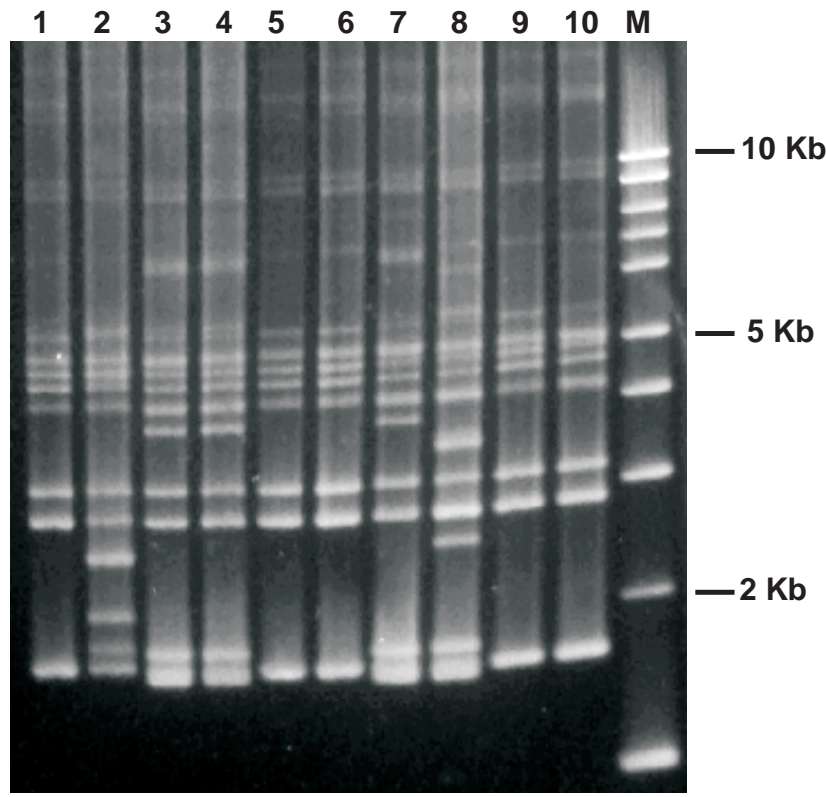

FIG. 2 - Perfil eletroforético do DNA amplificado por PCR de regiões repetidas Pot2 dos isolados monospóricos de Pyricularia grisea. Os números 1 a 10 representam os isolados 130, 166, 105, 84, 103, 102, 88, 63, 127 e 67, respectivamente; a letra M, os marcadores de peso molecular (Kilobase DNA marker; Amersham Pharmacia). 
Padrão molecular e de virulência de isolados de Pyricularia grisea...

(A)

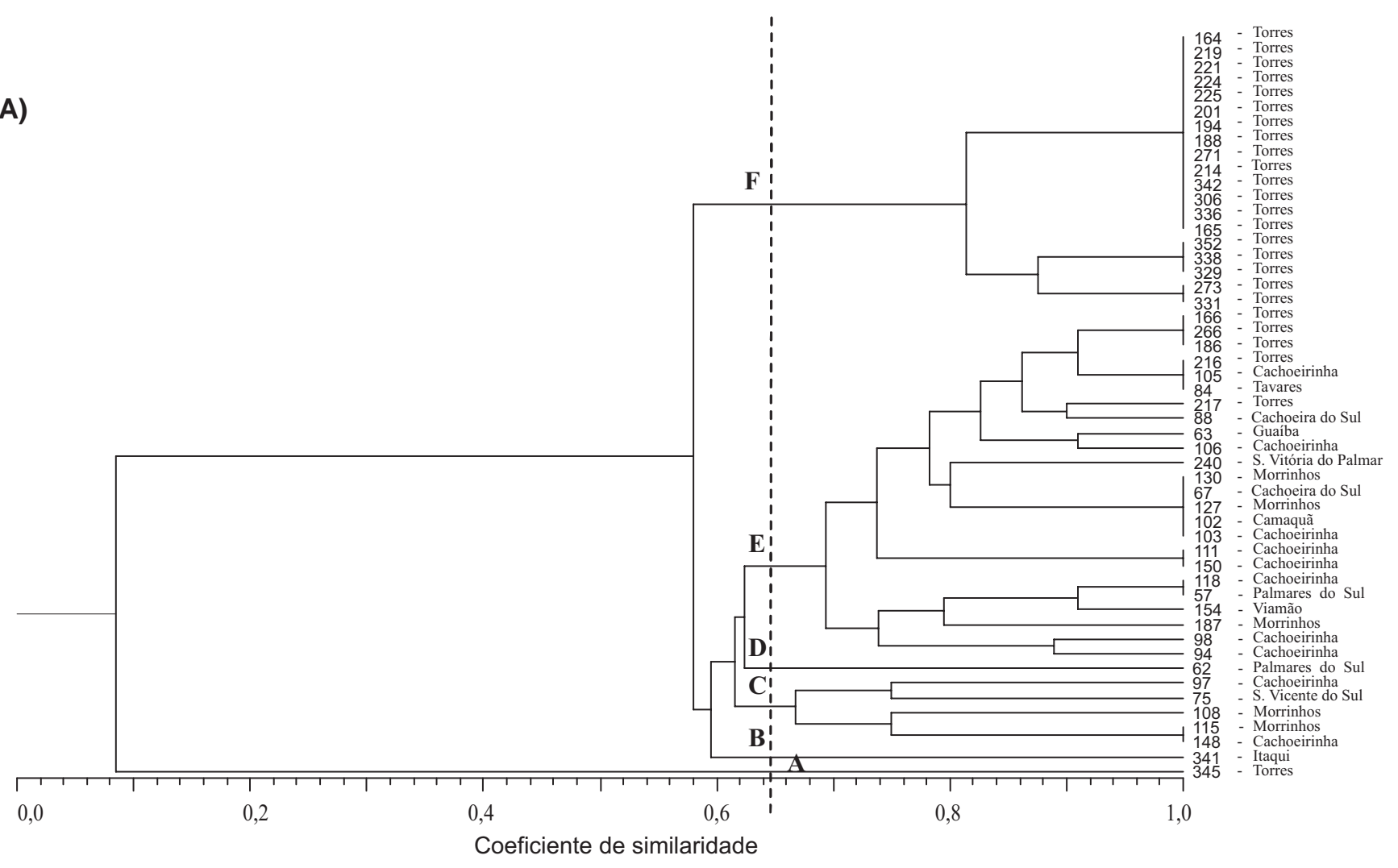

(B)

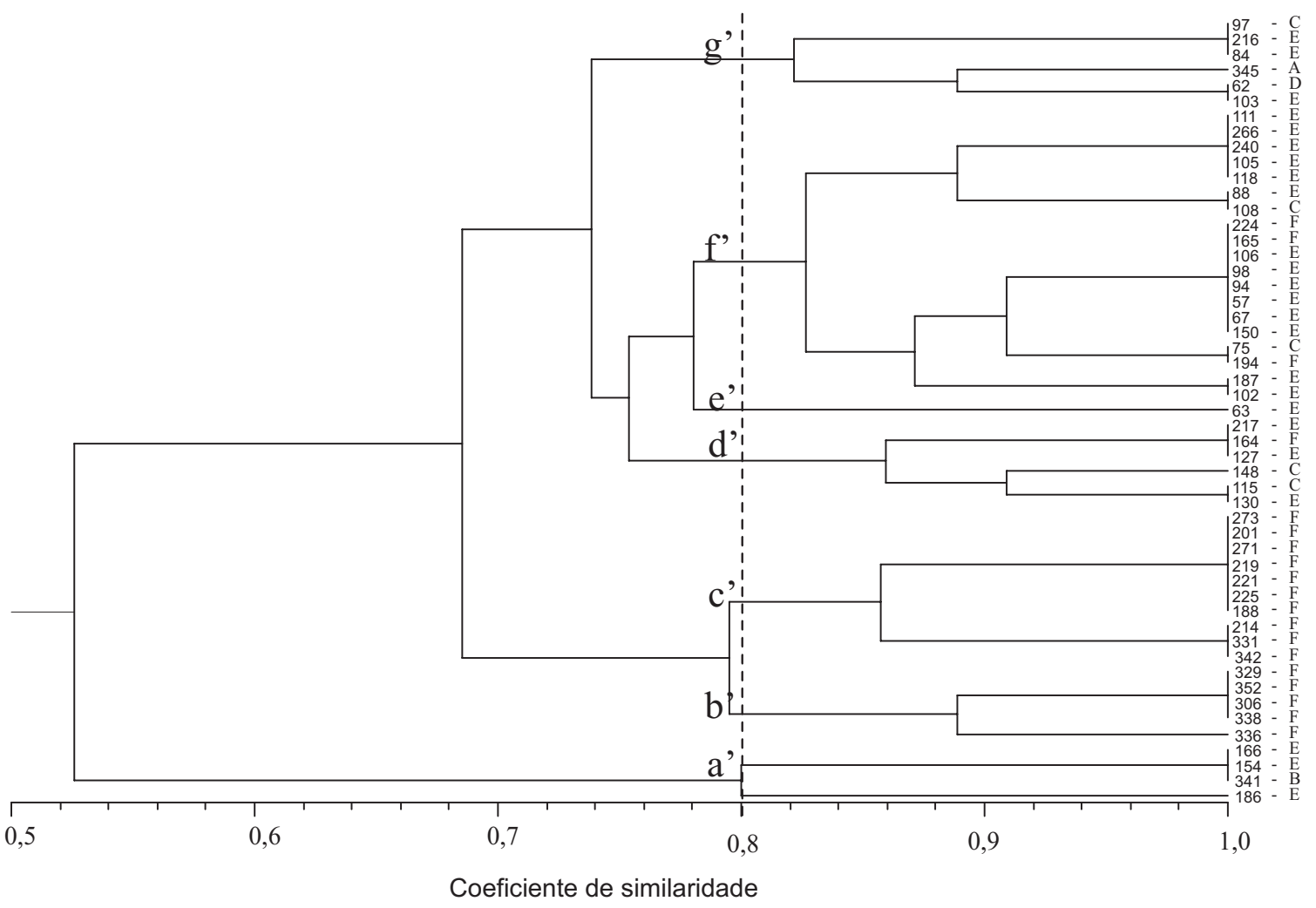

FIG. 3 - Dendrogramas baseados no perfil de amplificação do DNA de isolados monospóricos de Pyricularia grisea através de rep-PCR (A) e na reação de linhas isogênicas submetidas à inoculação com os mesmos isolados (B). As letras maiúsculas representam as linhagens seguidas do município de origem de cada isolado e, as minúsculas, os grupos de virulência do patógeno. 


\section{DISCUSSÃO}

Devido à baixa proporção de isolados identificados como pertencentes às linhagens $\mathrm{A}, \mathrm{B}, \mathrm{C}$ e D não foi possível estabelecer ao menos uma tendência do espectro de virulência dessas linhagens em relação às linhas isogênicas utilizadas no experimento. No entanto, no caso das linhagens E e F, em que a grande maioria dos isolados foram classificados, os padrões de virulência destas duas linhagens foram melhor estabelecidos e diferenciados entre si. Nesse aspecto, a principal diferença observada foi a reação da linha isogênica C 104 LAC em que se verificou uma acentuada variação na proporção de reações de compatibilidade entre as duas linhagens. Conforme pode ser observado na Tabela 1, enquanto que todos os isolados da linhagem E produziram reações de compatibilidade na linhagem C 104 LAC, somente quatro dos 19 isolados da linhagem F, isto é, 20\%, produziram o mesmo tipo de reação na mesma linhagem. Sem dúvida, esta interação linhagem-linha isogênica caracteriza uma situação compatível com modelo gene a gene proposto por Flor (1955), e que já foi demonstrado na interação arroz-P. grisea (Thompson \& Burdon, 1992).

Outra diferença considerável entre as linhagens E e $\mathrm{F}$ foi que nenhum dos isolados da linhagem $\mathrm{F}$ provocou reações de compatibilidade na linha isogênica C 101 A51, entretanto três isolados da linhagem E causaram reações compatíveis nesse genótipo. Além disso, somente $40 \%$ dos isolados da linhagem E promoveram reações de compatibilidade na linha isogênica C 105 TTP enquanto que todos os da linhagem $\mathrm{F}$ promoveram reações compatíveis. Também se verificou que todos os isolados das linhagens $A, B, C$ e D promoveram reações de compatibilidade na linha isogênica $C$ 104 LAC.

Caso fosse confirmada a menor ocorrência das linhagens A, B, C e D no Rio Grande do Sul, através de levantamentos com maior número de isolados de todas as regiões orízicolas do estado, não significaria que tais linhagens não tivessem importância epidemiológica para causar o incremento da doença nas lavouras de arroz do Rio Grande do Sul. O aumento da população dessas linhagens poderia ocorrer a qualquer momento desde que fosse realizado o plantio intenso e contínuo de genótipos que favorecessem o aumento da população das mesmas.

A caracterização das linhagens de $P$. grisea e a determinação dos seus respectivos espectros de virulência em linhas isogênicas se constituem em importantes estratégias para compreender a variabilidade da população do patógeno. Também servem para indicar quais sãos os genes de resistência mais efetivos para controlar a doença nos locais de onde os isolados do fungo foram obtidos o que se constitui em uma importante etapa para que se adote a estratégia da piramidização de genes de resistência. Entretanto, a variabilidade do fungo determinada em um levantamento como o apresentado neste trabalho representa apenas uma amostragem em um determinado período de tempo. É muito provável que novos levantamentos, feitos com isolados de $P$. grisea obtidos de amostras mais recentes, já registrem mudanças na distribuição das linhagens do fungo, indicando que para monitorar a dinâmica da população do patógeno existe a necessidade de que as avaliações sejam bastante freqüentes.

A única relação estabelecida entre as seis linhagens e os municípios onde as amostras foram coletadas foi entre a linhagem F e o município de Torres. Tal situação indica que a distribuição de linhagens no Rio Grande do Sul pode não ser homogênea, embora esta análise seja desfavorecida pelo pequeno número de isolados identicados como pertencentes às linhagens $\mathrm{A}, \mathrm{B}, \mathrm{C}$ e $\mathrm{D}$ e, também, pelo número total de isolados utilizados ser relativamente baixo. A ocorrência da linhagem F somente em Torres pode estar associado, entre outros fatores, à utilização quase que exclusiva no município do sistema de cultivo de arroz irrigado denominado prégerminado. Caber destacar que este sistema, que ocupa em torno de $10 \%$ da área de cultivo no estado, adota condições como época de semeadura, cultivares, manejo de água e de solo bastante diferenciados dos demais sistemas de cultivo utilizados no Rio Grande do Sul.

Em nenhuma das linhas isogênicas verificou-se reações de incompatibilidade para todos os isolados utilizados no experimento. Isto indica a dificuldade para se obter êxito no controle da brusone no Rio Grande do Sul somente pela ação individual de algum dos genes de resistência presentes em cada uma das linhas isogênicas utilizadas neste experimento. Assim, para a obtenção de resistência genética à brusone no estado, é necessário que os procedimentos sejam orientados para a geração de genótipos que possuam uma combinação de genes que seja efetiva contra todos os variantes do patógeno no estado. Nesse aspecto, foi o alelo $\mathrm{Pi}$-2, presente na linha

TABELA 1 - Espectro de virulência das linhagens de Pyricularia grisea em linhas isogênicas de arroz (Oryza sativa)

\begin{tabular}{|c|c|c|c|c|c|c|c|c|}
\hline \multirow{2}{*}{ Linha isogênica } & \multirow{2}{*}{ Gene de resist ência } & \multicolumn{6}{|c|}{ "Linhagens } & \multirow{2}{*}{ Total } \\
\hline & & $\mathbf{A}$ & B & $\mathbf{C}$ & D & $\mathbf{E}$ & $\mathbf{F}$ & \\
\hline C 101 A51 & $P i-2$ & $0 / 1^{*}$ & $0 / 1$ & $3 / 5$ & $0 / 1$ & $3 / 24$ & $0 / 19$ & $6 / 51$ \\
\hline C $101 \mathrm{PKT}$ & $P i-4 \mathrm{a}$ & $1 / 1$ & $0 / 1$ & $5 / 5$ & $1 / 1$ & $17 / 24$ & $19 / 19$ & $43 / 51$ \\
\hline C 104 LAC & $P i-1$ & $1 / 1$ & $1 / 1$ & $5 / 5$ & $1 / 1$ & $24 / 24$ & $4 / 19$ & $36 / 51$ \\
\hline C 104 PKT & $P i-3$ & $1 / 1$ & $0 / 1$ & $2 / 5$ & $0 / 1$ & $15 / 24$ & $11 / 19$ & $29 / 51$ \\
\hline C 105 TTP & $P i-4 b+?$ & $0 / 1$ & $0 / 1$ & $3 / 5$ & $0 / 1$ & $11 / 24$ & $19 / 19$ & $33 / 51$ \\
\hline IR 1529 & $P i-11+?$ & $1 / 1$ & $0 / 1$ & $2 / 5$ & $1 / 1$ & $1 / 24$ & $6 / 19$ & $11 / 51$ \\
\hline
\end{tabular}

* Proporção de reações compatíveis produzidas pelos isolados de cada linhagem. 
Padrão molecular e de virulência de isolados de Pyricularia grisea...

isogênica C 101 A51, que demonstrou maior eficiência para impedir o desenvolvimento do patógeno, uma vez que somente seis isolados produziram reações de compatibilidade neste genótipo. As reações verificadas nesta linha isogênica, além de terem sido difíceis de serem reproduzidas em inoculações subseqüentes, sempre foram do tipo 4, de acordo com a escala preconizada pelo sistema internacional de avaliação de doenças do arroz (International Rice Research Institute, 1996). Deve-se considerar, portanto, a possibilidade de incorporação deste alelo em cultivares de arroz destinadas ao plantio no Rio Grande do Sul tal como fora sugerido por Filippi \& Prabhu (2001) para as cultivares destinadas ao cultivo de sequeiro na Região Centro-Oeste do Brasil. Especificamente esse alelo caracterizase com integrante indispensável em um programa de piramidização de genes. Diante dessa possibilidade, uma estratégia moderna para que se possa monitorar a incorporação do referido alelo em genótipos de arroz destinados à geração de novas cultivares deve contar com o auxílio do melhoramento assistido por marcadores moleculares.

A opção pela SR-Pot2 como marcador molecular para execução deste trabalho está relacionada às características que a mesma tem demonstrado como ferramenta para estudo da filogenia do fungo $P$. grisea. A SR-Pot2 se constitui em um componente presente no genoma do fungo desde suas fases mais iniciais de evolução, além de gerar padrões moleculares que permitem diferenciar isolados obtidos do arroz daqueles oriundos de outras espécies de plantas (George et al., 1998; Zeigler, 1998). Além disso, a caracterização molecular da população do fungo, feitas pelo uso de marcadores moleculares baseados em seqüências de DNA repetidas, incluindo-se a SR-Pot2, tem confirmado a natureza clonal das linhagens, embora já tenha sido demonstrado que os padrões moleculares de cada linhagem não sejam totalmente invariáveis (Zeigler, 1998). Assim, atualmente o uso de marcadores moleculares baseados em seqüências repetidas constitui-se na estratégia disponível mais factível e precisa para identificar as eventuais trocas genéticas na população do fungo sejam elas oriundas de mutações, seleções ou recombinações (sexual ou parassexual). No entanto, como pode ser verificado no presente trabalho, ao se comparar os grupos formados em função dos padrões moleculares e virulência dos isolados, constatou-se que a relação entre os dois critérios não é exata ou totalmente correspondente. Isto é demonstrado na Tabela 1 em que se observa a ausência de um padrão específico de reação de cada linha isogênica aos isolados das duas linhagens com maior número de isolados identificados, isto é, a E e F. Também foi observado que todas as linhagens possuem isolados que pertenceram a grupos de virulência que são comuns a pelo menos mais uma linhagem (Figura 4). Embora alguns autores tenham demonstrado que esta relação entre filogenia e fenótipo seja relativamente simples (Levy et al., 1991; Zeigler, 1998), a maioria dos trabalhos tem demonstrado que os isolados de uma mesma linhagem apresentam variação para a virulência (Levy et al., 1993; Xia et al., 1993) da mesma forma que é demonstrado no presente trabalho.

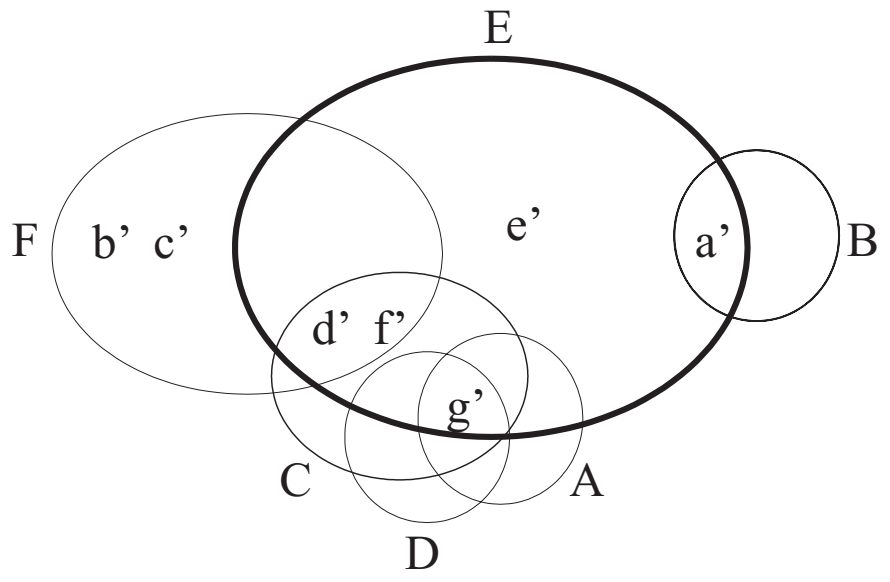

FIG. 4 - Representação esquemática da relação entre as linhagens e grupos de virulência do patógeno (Pyricularia grisea). As letras maiúsculas e minúsculas representam as linhagens e os grupos de virulência do patógeno, respectivamente.

\section{REFERÊNCIAS BIBLIOGRÁFICAS}

ATKINS, J.G., ROBERT, A.L., ADAIR, C.R., GOTO, K., KOSAKA, T., YANAGIDA, P., YAMADA, M. \& MATSUMOTO, S. International set of rice varieties for differentiating races of Pyricularia oryzae. Phytopathology 57:297301. 1967.

CHEN, D.H., ZEIGLER, R.S., LEUNG, H. \& NELSON, R.J. Population structure of Pyricularia grisea in two screening sites in Philippines. Phytopathology 85:1011-1020. 1995.

CORREA-VICTORIA, F. J. \& ZEIGLER, R. S. Pathogenic variability in Pyricularia grisea at a rice blast "hot spot" breeding site in eastern Colombia. Plant Disease 77:1029-1035. 1993.

FILIPPI, M.C. \& PRABHU, A.S. Phenotypic virulence analysis of Pyricularia grisea isolates from Brazil upland rice cultivars. Pesquisa Agropecuária Brasileira 36:27-35. 2001.

FLOR, H.H. Host-parasite interaction in flax rust. Its genetics and other implications. Phytopathology 45:680-685.1955.

GEORGE, M.L.C., NELSON, R.J., ZEIGLER, R.S. \& LEUNG, H. Rapid population analysis of Magnaporthe grisea by using repPCR and endogenous repetitive DNA sequences. Phytopathology 88:223-229. 1988.

INUKAI, T., NELSON, R.J., ZEIGLER, R.S., SARKARUNG, S. TAKAMURE, I. \& KINOSHITA, T. Differentiation of pathogenic races of rice blast fungus by using near-isogenic lines with Indica genetic background. Journal of the Faculty of Agriculture Hokkaido 66:27-35. 1994.

INTERNATIONAL RICE RESEARCH INSTITUTE. Standard evaluation system for rice. $4^{\text {nd }}$ ed. Manila. 1996.

KACHROO, P., LEONG, S.A. \& CHATHOO, B.B. Pot2, an inverted repeat transposon from the rice blast fungus Magnaporthe grisea. Molecular General Genetics 245:39-48. 1994.

LEVY, M., CORREA-VICTORIA, F.S., ZEIGLER, R.S., XU, S. \& HAMER, J.E. Genetic diversity of the rice blast fungus in a disease nursery in Colombia. Phytopathology 83:1427-1433. 1993.

LEVY, M., ROMAO, J., MARCHETTI, M.A. \& HAMER, J.E. DNA fingerprinting with a dispersed repeated sequences resolves 
J.L.N. Maciel et al.

pathotype diversity in the rice blast fungus. Plant Cell 3:95-102. 1991.

MACKILL, D.J. \& BONMAM, J.M. Inheritance of blast resistance in near-isogenic lines in rice. Phytopathology 82:746-749.1992.

MEKWATANAKARN, P., KOSITRANA, W \& ZEIGLER, R.S. Pathotype and avirulence gene diversity of Pyricularia grisea in Thailand as determined by rice lines near-isogenic for major resistance genes. Plant Disease 84:60-70. 2000.

PRABHU, A.S., FILIPPI, M.C., ARAUJO, L.G. \& FARIA, J.C. Caracterização genética e fenotípica de isolados de Pyricularia grisea coletados em lavouras das cultivares Epagri 108 e 109 no Estado de Tocantins. Fitopatologia Brasileira 27:566-573. 2002.

SCOOT, R.P., ZEIGLER, R.S. \& NELSON, R.J. A procedure for mini-scale preparation of Pyricularia grisea DNA. International Rice Research Notes 18:47-48. 1993.

SNEATH, P.H.A. \& SOKAL, R.R. Numerical Taxonomy. W.H. Freeman and Company. 1973.
THOMPSON, J.N. \& BURDON, J.J. Gene-for-gene coevolution between plants and parasites. Nature 360:121-125.1992.

TUITE, J. Plant Pathological Methods, Fungi and Bacteria. Minneapolis. Burgess Publishing. 1969.

Van ETTEN, J.L. \& DALY, J.M. Production of host-specific toxins by Helminthosporium victoriae and $H$. maydis in liquid shake culture. Phytopathology 70:727-729. 1980.

XIA, J.Q., CORREL, J.C., LEE, F.N., MARCHETTI, M.A. \& RHOADS, D.D. DNA fingerprinting to examine microgeographic variation in the Magnaporthe grisea (Pyricularia grisea) population in two rice fields in Arkansas. Phytopathology 83: 1029-1035. 1993.

ZEIGLER, R.S., CUOC, L.X., SCOOT, R.P., BERNARDO, M.A., CHEN, D.H., VALENT, B. \& NELSON, R.J. The relationship between lineage and virulence in Pyricularia grisea in the Philippines. Phytopathology 85:443-451. 1995.

ZEIGLER, R.S. Recombination in Magnaporthe grisea. Annual Review or Phytopathology 36:249-275. 1998. 